\title{
A survey of internal and family medicine residents: Assessment of disability-specific education and knowledge.
}

\author{
Michael D Stillman \\ Thomas Jefferson University \\ Nethra Ankam \\ Thomas Jefferson University \\ Michael Mallow \\ Thomas Jefferson University \\ Maclain Capron \\ Thomas Jefferson University \\ Steve Williams \\ Thomas Jefferson University \\ Follow this and additional works at: https://jdc.jefferson.edu/rmfp \\ Part of the Rehabilitation and Therapy Commons \\ Let us know how access to this document benefits you
}

\section{Recommended Citation}

Stillman, Michael D; Ankam, Nethra; Mallow, Michael; Capron, Maclain; and Williams, Steve, "A survey of internal and family medicine residents: Assessment of disability-specific education and knowledge." (2020). Department of Rehabilitation Medicine Faculty Papers. Paper 42. https://jdc.jefferson.edu/rmfp/42

This Article is brought to you for free and open access by the Jefferson Digital Commons. The Jefferson Digital Commons is a service of Thomas Jefferson University's Center for Teaching and Learning (CTL). The Commons is a showcase for Jefferson books and journals, peer-reviewed scholarly publications, unique historical collections from the University archives, and teaching tools. The Jefferson Digital Commons allows researchers and interested readers anywhere in the world to learn about and keep up to date with Jefferson scholarship. This article has been accepted for inclusion in Department of Rehabilitation Medicine Faculty Papers by an authorized administrator of the Jefferson Digital Commons. For more information, please contact: JeffersonDigitalCommons@jefferson.edu. 


\section{A Survey of Internal and Family Medicine Residents: Assessment of Disability- Specific Education and Knowledge}

\section{Authors:}

1) Michael D. Stillman, MD (corresponding) $)^{1,2}$

1100 Walnut Street, Suite 601

Philadelphia, PA 19107 USA

Michael.stillman@jefferson.edu

(p) 2159553523

(f) 2159556023

2) Nethra Ankam, $\mathrm{MD}^{2}$

nethra.ankam@jefferson.edu

3) Michael Mallow, $\mathrm{MD}^{2}$

michael.mallow@jefferson.edu

4) Maclain Capron ${ }^{2}$

maclain.capron@jefferson.edu

5) Steve Williams, $\mathrm{MD}^{2}$

steve.r.williams@jefferson.edu 
${ }^{1}$ Department of Internal Medicine, Sidney Kimmel Medical College, 1100 Walnut Street, Suite 601 Philadelphia, PA 19107 USA

${ }^{2}$ Department of Rehabilitation Medicine, Sidney Kimmel Medical College, 25 South $9^{\text {th }}$ Street, Philadelphia, PA 19107 USA

None of the authors has financial support related to this project or manuscript. None of the authors has a conflict of interest.

Abstract Word Count: 250

Manuscript Word Count: 2624

References: 40

Tables: 3

Keywords:

Graduate Medical Education; Undergraduate Medical Education; Disability Training 


\title{
A Survey of Internal and Family Medicine Residents: Assessment of Disability- Specific Education and Knowledge
}

\begin{abstract}
:

\section{Background:}

The literature suggests that primary care physicians are inadequately educated in the care of people with disabilities. No study to date has evaluated whether internal medicine (IM) and family medicine (FM) residents have received disability-specific education or their level of comfort in caring for people with disabilities.
\end{abstract}

\section{Objectives:}

To assess IM and FM residents' receipt of disability-specific education during medical school and residency; to evaluate their self-reported comfort in managing secondary effects of disability and in coordinating therapies and services for individuals with disabilities; to gauge their interest in receiving disability-specific education.

\section{Methods:}

An on-line survey was distributed to house officers at a convenience sample of ten academic IM and FM residency programs in the northeastern United States. Participants 
$(n=176)$ were asked about their socio-demographic and training-specific characteristics and their level of comfort in managing second effects of disability and coordinating care and services for individuals with disabilities. Chi Square tests were used to compare participant characteristics and outcomes.

\section{Results:}

Few participants had received disability-specific education during medical school or residency (34.6\% and $11.2 \%$, respectively), and nearly all (96.0\%) expressed interest in receiving more. Small minorities reported feeling comfortable managing common secondary effects of disability or in coordinating therapies and services for individuals with disabilities.

\section{Conclusion:}

Although one-fifth of adult Americans have a disability, few of our participating IM and FM residents had received disability-specific education or felt comfortable managing the care of people living with disabilities. Our results indicate a need to develop and disseminate disability-specific curricula.

\section{Keywords:}

Graduate Medical Education; Undergraduate Medical Education; Disability Training 


\section{INTRODUCTION:}

People with disabilities have difficulties accessing and obtaining outpatient health care services. Facing structural and attitudinal obstacles to care (1-5) and physicians who under-estimate or are unaware of these barriers (6), they are often given incomplete care rather than being appropriately accommodated $(7,8)$. While the Americans with Disabilities Act (ADA) prohibits discrimination against people with disabilitiesincluding in their efforts to obtain health care (9)-medical practice administrators are largely unfamiliar with this law $(7,8)$.

Even when people with disabilities are able to access health care, it is often less than thorough and equitable. Chan et al found that Medicare beneficiaries with a greater number of activities of daily living (ADL) limitations receive fewer preventive services that do those with fewer limitations (10), and several authors have shown that people with a variety of mobility disabilities—-particularly women—receive fewer cancer screenings $(1,11,12)$ and vaccinations $(13)$ than do those without disabilities. In a study of 201 individuals with disabilities in the Toronto area, 22\% felt they had received inadequate primary health care due solely to their disability (3). In a study of 108 people with spinal cord injury (SCI), nearly $90 \%$ reported being routinely examined while fully clothed and seated in their wheelchair and $66 \%$ believed they had been provided incomplete care as a result of their injury (12). 
While the discrepancies in health care provided to people with and without disabilities may be multifactorial $(4,14)$, it is known that many physicians are inadequately educated about the care of people living with disabilities. In Seidel et al's survey querying disability awareness programs in medical schools, only $52 \%$ of responding institutions (45\% total response rate) reported having such a program (15). In a regional survey of 501 primary care physicians (PCPs) in California, only $22.8 \%$ had received disabilityspecific education during medical school and only $34.1 \%$ had received it during residency (16). Meanwhile, in a national study of 432 wheelchair users, only $57 \%$ felt that their PCP had an inadequate understanding of their health concerns and only $61 \%$ were satisfied with the care he/she had provided to them (7). In Hamilton et al's study of 142 individuals with SCI, one-third reported that their PCPs were not knowledgeable about their health care needs (2). In Morrison et al's qualitative study of communitydwelling adults with disabilities, many spoke of having to teach their physicians how to care for them and of their physicians' inability to understand their concerns (5).

Lack of equitable health care may have social, financial, psychological, and physical consequences for people with disabilities (17), yet few authors have inquired about generalists' comfort in managing various aspects of the health care needs of their patients with disabilities. This is particularly important, as $22 \%$ of American adults have a disability (18) and nearly $1.5 \%$ have mobility limitations resulting in wheelchair or scooter use (19). We developed and distributed an 18-item survey meant to determine the following: 1) whether IM and FM residents have received disability-specific education 
during medical school or residency; 2) their level of comfort in managing a number of common secondary effects of physical disability; 3) their familiarity with and ability to coordinate commonly offered therapies and home and community services, and; 4) their interest in receiving additional training in the care of people with disabilities. Our hope was that our results would raise interest in improving disability education for physicians while providing guidance in generating disability-focused curricula.

\section{METHODS:}

\section{Setting and Participants:}

We contacted program directors of a convenience sample of 12 IM and FM residency programs in the northeastern United States and two declined to participate. The remaining 10 agreed to send their 698 house officers a first round email with the survey embedded, and that effort yielded 68 responses. A second "reminder" email was sent two months later and yielded an additional 108 replies for a total $n$ of 176 and a response rate of 25.2\%. The survey was available from November, 2019 through January, 2020.

\section{Interventions:}

The authors reviewed the literature addressing disability-specific medical education $(15,16,20-22)$ and physicians' comfort in managing common secondary effects of 
disabilities (13). Using that foundation and our own clinical experience, we drafted a first version of the survey that addressed participants' demographic data, educational experiences, comfort in helping care for people with disabilities, and interest in learning more about the care of individuals with disabilities. We also sought input from several persons living with disabilities and from colleagues with expertise in the areas of undergraduate and graduate medical education, the clinical care of people with disabilities, and independent and community living. Utilizing their collected insights, we finalized the survey (Appendix) in which "disability" was defined as a "physical or mental impairment that substantially limits one or more major life activities" (23). The sole inclusion criterion for completing the survey was being a house officer at a participating IM or FM training program.

\section{Outcomes Measured:}

Participants were asked about the type of residency program in which they were enrolled, their level of training, their personal experiences with disability, their gender identity, and whether they were interested in a career in primary care. They were then asked whether or not they had received disability-specific education during medical school or residency and to rate their level of comfort in managing secondary effects of disability and in coordinating therapies and home and community services. Finally, they were asked whether or not they would consider completing a one-year fellowship in the care of people with disabilities. 


\section{Analysis of the Outcomes:}

The categorical data collected in this survey were deemed best suited to Chi Square tests, which were used to compare participant characteristics and outcomes. Survey responses were reviewed for completeness. The two questions in which respondents were asked to rate their self-comfort in providing care and coordinating services for individuals with disabilities utilized the 5-point Likert Scale. In these items assessing comfort, 1 indicated "Not at All," 2 indicated "Slightly," 3 indicated "Somewhat," 4 indicated "Very," and 5 indicated "Completely." For the purposes of analysis, the lower and upper values were grouped such that "Not at All" and "Slightly" were combined into an "Uncomfortable" category, "Very" and "Completely" were combined into a "Comfortable" category, and the central category of "Somewhat" was not grouped.

\section{IRB Statement:}

No identifying data were collected from participants, and their consent was implied by their having opened and worked on the survey. This study was reviewed and deemed exempt by the Thomas Jefferson University IRB on October 24, 2019, Reference Number 19E.779.

\section{RESULTS:}


Of the 176 respondents, $81.8 \%$ were IM house officers, $57.5 \%$ identified as female (41.3\% male; $1.2 \%$ non-binary/fluid), and $90.6 \%$ had allopathic (MD) rather than osteopathic (DO) degrees. There was a near-even distribution of participants' level of training (37.9\% PGY-1; 34.3\% PGY-2; 27.8\% PGY-3), 27.8\% planned to have a career in primary care (58.0\% answered "no"; $14.2 \%$ were unsure), and while $25.1 \%$ had been a caretaker or a family member of a person with a disability, only $2.4 \%$ had a disability, themselves (Table 1).

While nearly all respondents had helped to care for patients with disabilities in the outpatient and inpatient settings (90.9\% and 99.4\%, respectively), relatively few $(25.2 \%)$ had received specific education surrounding "legally required accommodations for people living with disabilities" or "the care of people living with disabilities" $(34.6 \%$ during medical school; $11.2 \%$ during residency). A majority felt that the institution at which they work is "sensitive to the needs of people with disabilities" (55.3\% "Yes"; 10.7\% "No"; 34\% "Cannot Accurately Assess") and is "adequately accessible" for people with disabilities (71.1\% "Yes"; 9.4\% "No"; 19.5\% "Cannot Accurately Assess"). Nearly all participants (96\%) felt they would benefit from "additional instruction or access to resources surrounding the care of people living with disabilities."

Respondents' level of comfort in identifying, evaluating, and managing potential secondary effects of disability were measured utilizing the 5-point Likert Scale. While 65.6\% felt comfortable managing depression, far fewer felt comfortable managing neuropathic $(32.9 \%)$ or somatic $(20.8 \%)$ pain, skin integrity $(28.9 \%)$, neurogenic bladder 
(13.1\%), spasticity (8.5\%), autonomic dysregulation $(6.5 \%)$, or neurogenic bowel $(6 \%)$ (Table 2).

We used the same scale to determine participants' comfort with evaluating their patients' needs for therapies, adaptive equipment, and community and home-based services (Table 3). While a plurality (45.8\%) felt comfortable evaluating the need for physical therapy, far fewer were comfortable evaluating the need for speech and language therapy, occupational therapy, and vocational rehabilitation $(23.7 \%, 19.4 \%$, and $7.6 \%$, respectively). Smaller percentages felt comfortable evaluating their patients' needs for home health services (16.7\%), durable medical equipment (12.8\%), accessible transportation (12.4\%), home modifications $(7.3 \%)$, communication devices $(7.3 \%)$, and mobility devices (5.5\%). Seventy-eight percent of participants reported not understanding how to access care coordination and community-based services for people with disabilities.

A chi-square test of independence showed that there was no significant association between comfort in providing or coordinating care for people with disabilities and participant characteristics including MD vs DO, $\chi^{2}(1, N=151)=3.211, p=.073$, gender, $\chi^{2}(1, N=151)=4.669, \mathrm{p}=.097, \mathrm{IM}$ vs FM residency training, $\chi^{2}(1, N=151)=0.127, \mathrm{p}$ $=.722$, having been a caretaker or family member of someone with a disability, $\chi^{2}(1, N=$ $151)=2.788, p=.095$, or having received formal education in the care of people with disabilities, $\chi^{2}(1, N=151)=1.727, p=.189$. Additional analyses revealed that "upper level" house officers (combination of responses from PGY-2 and PGY-3 participants) 
were no more comfortable than were interns in managing secondary effects of disability or in seeing to their patients' therapeutic, equipment, and service-based needs (Tables 2 and 3). Twenty-seven percent of respondents expressed potential interest in a one-year fellowship-level opportunity to help physicians provide better care for individuals with disabilities. Those planning a career in primary care were significantly more likely to express interest in such an opportunity than were those who were not, $\chi^{2}(2, N=148)=$ $6.726, p=.035$.

\section{DISCUSSION:}

In this novel survey of house officers in IM and FM residency programs, respondents identified significant gaps in their education concerning the care of people with disabilities at both the undergraduate (UME) and graduate medical education (GME) levels. This educational paucity corresponded with low rates of comfort in managing secondary effects of disability and coordinating therapies and home and community based services for people living with disabilities.

Low rate of comfort in managing even common secondary effects of disability portends poorly for PCPs' ability to provide thorough and equitable care to our patients with a variety of complex medical needs. It is expected that trainees would be less familiar with autonomic dysregulation, as this is most often, though not exclusively, seen in people with SCI. However, many primary care patients have somatic and neuropathic pain (24), 
and skin break down, spasticity, and neurogenic bladder and bowel may accompany a variety of chronic medical conditions including Parkinson's Disease, Cerebral Palsy, stroke, Multiple Sclerosis, Amyotrophic Lateral Sclerosis, and advanced Diabetes Mellitus (25-35). While rehabilitation physicians are specifically trained to care for individuals with disabilities and to help ameliorate secondary effects of disability, there are approximately 10,000 physiatrists in the United States (36) and tens of millions of people living with disabilities. It behooves generalist physicians, then, to be able to meaningfully assist in the care of their patients with disabilities and to understand basic principles of outpatient therapy and care coordination and management.

In our survey, we asked participants to describe any disability-specific education they had received during medical school. Several wrote that their schools had offered "built in portions of the curriculum," "electives in disability care," or "dedicated lectures and objective structure clinical examinations (OSCEs) addressing the challenges of accessing and navigating heath care for individuals with intellectual and physical disabilities." However, most respondents described scattered discussions or lectures, including a single session about "sensitivity and bias," a lecture about "functional status... and service animals," and a "simulation of what it would be like to be blind or deaf." Given that fewer than $35 \%$ of our subjects had been offered any disability-focused materials in medical school, and that those materials were neither standardized nor thorough, it is not surprising that having received disability-specific education during medical school did not correlate with respondents' comfort in caring for people with disabilities. In addition, the content of their remembered training is in line with a recent review of the literature on 
disability education in medical schools that found that published curricula are more focused on changing attitudes than on imparting skills (21).

While the Liaison Committee on Medical Education (LCME) does not mandate that medical schools teach disability-specific curricula, it does direct them to offer content on "preventive, acute, chronic, and rehabilitative care" and the recognition of disparities in health care and potential methods to eliminate them (37). Given that the substantial percentage of Americans living with a disability are at risk for receiving inequitable care, there is a pressing need to develop and offer for distribution a short yet comprehensive curriculum in disability care. Certain working groups have developed disability competencies for health care education (22) and strategies for incorporating them into existing UME curricula (21). However, there are significant barriers to implementing these strategies, including a perceived lack of time and support and the belief by UME leaders that a satisfactory disability-based curriculum can be delivered in only two or three hours (15).

The Alliance for Disability in Health Care Education has developed and published a set of core competencies on disability for health care education (38). While the majority of these standards pertain to patient-centered care, inter-professionalism, and the ability to coordinate care needs over the lifespan of individuals with disabilities, learners at the GME level may benefit from more clinically-oriented training. At our own institution, we are developing 2-month tracks within the IM and FM residency programs that will help house officers develop a basic understanding of the management of secondary effects of a 
variety of disabilities and the ability to help coordinate therapies and community-based services. However, we also believe that at institutions with departments of rehabilitation medicine, shorter electives sponsored by those departments could be critically important in helping future generations of PCPs be more sensitive to and aware of the needs of individuals with disabilities. It is notable that nearly every respondent to our survey expressed interest in receiving additional disability-specific education, and that even those who planned to pursue a fellowship understood that their patient care would be enhanced by such training.

This study has several important limitations. First, we used a convenience sample of geographically limited residency programs. It could be that in the absence of LCME mandates, educational emphases differ subtly by region. Second, we only polled house officers in IM and FM programs, eliminating responses from physicians who may have used elective time during medical school to prepare to apply to residencies in rehabilitation medicine or neurology and who may, then, have been exposed to disabilityspecific curricula at the UME level. Third, despite having distributed our survey twice, our response rate was sub-optimal, and it may be that only those with specific interest in the care of people with disabilities opened and completed the survey. However, the average response rate to internet-based surveys is 33\% (39), and we implemented recruiting strategies known to optimize participation including personalizing our request, sending a reminder message, and keeping the survey brief (40). Finally, our survey was incomplete, as we did not query participants about the care of people with sensory and intellectual and development disabilities. 


\section{CONCLUSION:}

This effort has described wide spread deficiencies in disability-specific medical education and a broad interest by IM and FM trainees in enhancing their knowledge base and skills. More work in this area is clearly needed, particularly around development and dissemination of disability-based learning experiences and curricula and assessment of pre and post-intervention cognitive and diagnostic skills. 


\section{References:}

(1) Stillman MD, Bertocci G, Smalley C, Williams S, Frost KL. Healthcare utilization and associated barriers experienced by wheelchair users: A pilot study. Disabil Health J 2017 Oct;10(4):502-508.

(2) Hamilton R, Driver S, Noorani S, Callender L, Bennett M, Monden K. Utilization and access to healthcare services among community-dwelling people living with spinal cord injury. J Spinal Cord Med 2017 May;40(3):321-328.

(3) Veltman A, Stewart DE, Tardif GS, Branigan M. Perceptions of primary healthcare services among people with physical disabilities - part 1: access issues. MedGenMed 2001 Apr 6;3(2):18.

(4) Kroll T, Jones GC, Kehn M, Neri MT. Barriers and strategies affecting the utilisation of primary preventive services for people with physical disabilities: a qualitative inquiry. Health Soc Care Community 2006 Jul;14(4):284-293.

(5) Morrison EH, George V, Mosqueda L. Primary care for adults with physical disabilities: perceptions from consumer and provider focus groups. Fam Med 2008 Oct;40(9):645-651.

(6) Sanchez J, Byfield G, Brown TT, LaFavor K, Murphy D, Laud P. Perceived accessibility versus actual physical accessibility of healthcare facilities. Rehabil Nurs 2000 Jan-Feb;25(1):6-9.

(7) Frost KL, Bertocci G, PE, Stillman MD, Smalley C, MEng, et al. Accessibility of outpatient healthcare providers for wheelchair users: Pilot study. J Rehabil Res Dev 2015;52(6):653-662.

(8) Pharr JR. Accommodations for patients with disabilities in primary care: a mixed methods study of practice administrators. Glob J Health Sci 2013 Oct 8;6(1):23-32.

(9) U.S. Department of Justice. Access to medical care for individuals with mobility disabilities [Internet]. Washington (DC): U.S. Department of Justice. 2010; Available at: http://www.ada.gov/medcare_ta.htm. Accessed February 21, 2020.

(10) Chan L, Doctor JN, MacLehose RF, Lawson H, Rosenblatt RA, Baldwin LM, et al. Do Medicare patients with disabilities receive preventive services? A population-based study. Arch Phys Med Rehabil 1999 Jun;80(6):642-646.

(11) Lavela SL, Weaver FM, Smith B, Chen K. Disease prevalence and use of preventive services: comparison of female veterans in general and those with spinal cord injuries and disorders. J Womens Health (Larchmt) 2006 Apr;15(3):301-311. 
(12) Stillman MD, Frost KL, Smalley C, Bertocci G, Williams S. Health care utilization and barriers experienced by individuals with spinal cord injury. Arch Phys Med Rehabil 2014 Jun;95(6):1114-1126.

(13) Lofters A, Chaudhry M, Slater M, Schuler A, Milligan J, Lee J, et al. Preventive care among primary care patients living with spinal cord injury. J Spinal Cord Med 2019 Nov;42(6):702-708.

(14) Milligan J, Lee J. Enhancing primary care for persons with spinal cord injury: More than improving physical accessibility. J Spinal Cord Med 2016 Sep;39(5):496-499.

(15) Seidel E, Crowe S. The State of Disability Awareness in American Medical Schools. Am J Phys Med Rehabil 2017 Sep;96(9):673-676.

(16) Larson McNeal M, Carrothers L, Premo B. Providing Primary Health Care for People with Physical Disabilities: A Survey of California Physicians. 2002.

(17) Neri MT, Kroll T. Understanding the consequences of access barriers to health care: experiences of adults with disabilities. Disabil Rehabil 2003 Jan 21;25(2):85-96.

(18) Courtney-Long EA, Carroll DD, Zhang QC, Stevens AC, Griffin-Blake S, Armour BS, et al. Prevalence of Disability and Disability Type Among Adults--United States, 2013. MMWR Morb Mortal Wkly Rep 2015 Jul 31;64(29):777-783.

(19) LaPlante MP, Kaye HS. Demographics and trends in wheeled mobility equipment use and accessibility in the community. Assist Technol 2010 Spring;22(1):3-17; quiz 19.

(20) Ioerger M, Flanders RM, French-Lawyer JR, Turk MA. Interventions to Teach Medical Students About Disability: A Systematic Search and Review. Am J Phys Med Rehabil 2019 Jul;98(7):577-599.

(21) Ankam NS, Bosques G, Sauter C, Stiens S, Therattil M, Williams FH, et al. Competency-Based Curriculum Development to Meet the Needs of People With Disabilities: A Call to Action. Acad Med 2019 Jun;94(6):781-788.

(22) Bowen CN, Havercamp SM, Karpiak Bowen S, Nye G. A call to action: Preparing a disability-competent health care workforce. Disabil Health J 2020 May 14:100941.

(23) ADA Amendments Act of 2008. 2008; Available at:

eeoc.gov/laws/statutes/adaaa.cfm. Accessed March/6, 2020.

(24) Mills S, Torrance N, Smith BH. Identification and Management of Chronic Pain in Primary Care: a Review. Curr Psychiatry Rep 2016 Feb;18(2):22-015-0659-9.

(25) Izquierdo G. Multiple sclerosis symptoms and spasticity management: new data. Neurodegener Dis Manag 2017 Nov;7(6s):7-11. 
(26) Otero-Romero S, Sastre-Garriga J, Comi G, Hartung HP, Soelberg Sørensen P, Thompson AJ, et al. Pharmacological management of spasticity in multiple sclerosis: Systematic review and consensus paper. Mult Scler 2016 Oct;22(11):1386-1396.

(27) Bar-On L, Molenaers G, Aertbeliën E, Van Campenhout A, Feys H, Nuttin B, et al. Spasticity and its contribution to hypertonia in cerebral palsy. Biomed Res Int 2015;2015:317047.

(28) Chang E, Ghosh N, Yanni D, Lee S, Alexandru D, Mozaffar T. A Review of Spasticity Treatments: Pharmacological and Interventional Approaches. Crit Rev Phys Rehabil Med 2013;25(1-2):11-22.

(29) Hardiman O, Al-Chalabi A, Chio A, Corr EM, Logroscino G, Robberecht W, et al. Amyotrophic lateral sclerosis. Nat Rev Dis Primers 2017 Oct 5;3:17071.

(30) Ginsberg D. The epidemiology and pathophysiology of neurogenic bladder. Am J Manag Care 2013;19(10 Suppl):s191-6.

(31) Kim KJ, Jeong SJ, Kim JM. Neurogenic bladder in progressive supranuclear palsy: A comparison with Parkinson's disease and multiple system atrophy. Neurourol Urodyn 2018 Jun;37(5):1724-1730.

(32) Palma JA, Kaufmann H. Treatment of autonomic dysfunction in Parkinson disease and other synucleinopathies. Mov Disord 2018 Mar;33(3):372-390.

(33) Emmanuel A. Neurogenic bowel dysfunction. F1000Res 2019 Oct 28;8:10.12688/f1000research.20529.1. eCollection 2019.

(34) Preziosi G, Gordon-Dixon A, Emmanuel A. Neurogenic bowel dysfunction in patients with multiple sclerosis: prevalence, impact, and management strategies. Degener Neurol Neuromuscul Dis 2018 Dec 6;8:79-90.

(35) Deli G, Bosnyak E, Pusch G, Komoly S, Feher G. Diabetic neuropathies: diagnosis and management. Neuroendocrinology 2013;98(4):267-280.

(36) 2017 PM\&R Physician Compensation Survey Report. 2017; Available at: aapmr.org/docs/default-source/career-center/808520_2017-compensation-survey-v06ex-summary.pdf?sfvrsn=5bc2587c_0. Accessed June/26, 2020.

(37) Functions and Structure of a Medical School: Standards for Accreditation of Medical Education Programs Leading to the MD Degree. 2020; Available at: lcme.org/publications/. Accessed April/9, 2020.

(38) Alliance for Disability in Health Care Education: Core Competencies on Disability for Health Care Education. 2019. 
(39) Shih T, Fan X. Comparing Response Rates in E-Mail and Paper Surveys: A MetaAnalysis. Educational Research Review 2009;4(1):26-40.

(40) Saleh A, Bista K. Examining Factors Impacting Online Survey Response Rates in Educational Research: Perceptions of Graduate Students. Journal of MultiDisciplinary Evaluation 2017;13(29):63-74. 
Table 1: Participant Characteristics

\begin{tabular}{|l|l|l|}
\hline Question & Categories & $\mathrm{n}(\%)$ \\
\hline \multirow{2}{*}{$\begin{array}{l}\text { In which type of residency program } \\
\text { are you currently enrolled? }\end{array}$} & Internal Medicine & $144(81.8)$ \\
\cline { 2 - 3 } \multirow{2}{*}{$\begin{array}{l}\text { In which year of your residency are } \\
\text { you? }\end{array}$} & Family Medicine & $32(18.3)$ \\
\cline { 2 - 3 } & PGY-1 & $64(37.9 \%)$ \\
\cline { 2 - 3 } & PGY-3 & $58(34.3)$ \\
\hline \multirow{2}{*}{$\begin{array}{l}\text { Is your graduate degree in } \\
\text { allopathic (MD) or osteopathic } \\
\text { (DO) medicine? }\end{array}$} & Allopathic (MD) & $47(27.8 \%)$ \\
\cline { 2 - 3 } $\begin{array}{l}\text { Do you plan to have a career in } \\
\text { primary care? }\end{array}$ & Osteopathic (DO) & $154(90.6 \%)$ \\
\cline { 2 - 3 } & Yes & $16(9.4 \%)$ \\
\cline { 2 - 3 } $\begin{array}{l}\text { Have you been a caretaker for or } \\
\text { family member of a person living } \\
\text { with a disability? }\end{array}$ & Unsure & $47(27.8 \%)$ \\
\hline \multirow{2}{*}{\begin{tabular}{l} 
Do you have a disability? \\
\cline { 2 - 3 }
\end{tabular}} & Yes & $98(58.0 \%)$ \\
\hline \multirow{2}{*}{$\begin{array}{l}\text { With respect to gender, how do you } \\
\text { identify? }\end{array}$} & No & $24(14.2 \%)$ \\
\cline { 2 - 3 } & No & $425(25.1 \%)$ \\
\cline { 2 - 3 } & Female & $163(97.4 \%)$ \\
\cline { 2 - 3 } & Non-Binary/Fluid & $69(41.3 \%)$ \\
\hline
\end{tabular}


Table 2: Level of Comfort in Identifying, Evaluating, and Managing Secondary Effects of Disability

\begin{tabular}{|c|c|c|c|c|c|}
\hline & & \multicolumn{3}{|c|}{ Level of Comfort } & \multirow[b]{2}{*}{ Total N } \\
\hline $\begin{array}{c}\text { Secondary } \\
\text { Complications }\end{array}$ & $\begin{array}{c}\text { Year of } \\
\text { Residency }\end{array}$ & $\begin{array}{c}\text { Uncomfortable } \\
\mathrm{n}(\%)\end{array}$ & $\begin{array}{c}\text { Somewhat } \\
\text { Comfortable } \\
\mathrm{n}(\%)\end{array}$ & $\begin{array}{l}\text { Comfortable } \\
\mathrm{n}(\%)\end{array}$ & \\
\hline \multirow[t]{3}{*}{ Neurogenic Bowel* } & PGY1 & $28(57.1 \%)$ & $19(38.8 \%)$ & $2(4.1 \%)$ & 49 \\
\hline & $\begin{array}{c}\text { PGY2 \& } \\
\text { PGY3 }\end{array}$ & $55(65.5 \%)$ & $23(27.4 \%)$ & $6(7.1 \%)$ & 84 \\
\hline & Total & $83(62.4 \%)$ & $42(31.6 \%)$ & $8(6.0 \%)$ & 133 \\
\hline \multirow[t]{3}{*}{ Neurogenic Bladder } & PGY1 & $24(42.9 \%)$ & $28(50.0 \%)$ & $4(7.1 \%)$ & 56 \\
\hline & $\begin{array}{c}\text { PGY2 \& } \\
\text { PGY3 }\end{array}$ & $35(39.3 \%)$ & $39(41.1 \%)$ & $15(16.9 \%)$ & 89 \\
\hline & Total & $59(40.7 \%)$ & $67(46.2 \%)$ & $19(13.1 \%)$ & 145 \\
\hline \multirow[t]{3}{*}{ Spasticity* } & PGY1 & $25(46.3 \%)$ & $23(42.6 \%)$ & $6(11.1 \%)$ & 54 \\
\hline & $\begin{array}{c}\text { PGY2 \& } \\
\text { PGY3 }\end{array}$ & $55(49.6 \%)$ & $27(30.7 \%)$ & $6(7.4 \%)$ & 88 \\
\hline & Total & $80(56.3 \%)$ & $50(35.2 \%)$ & $12(8.5 \%)$ & 142 \\
\hline \multirow{3}{*}{$\begin{array}{c}\text { Autonomic } \\
\text { Dysregulation* }\end{array}$} & PGY1 & $29(58.0 \%)$ & $16(32.0 \%)$ & $5(10.0 \%)$ & 50 \\
\hline & $\begin{array}{c}\text { PGY2 \& } \\
\text { PGY3 }\end{array}$ & $51(58.6 \%)$ & $32(36.8 \%)$ & $4(4.6 \%)$ & 87 \\
\hline & Total & $80(58.4 \%)$ & $48(35.0 \%)$ & $9(6.6 \%)$ & 137 \\
\hline \multirow{3}{*}{$\begin{array}{c}\text { Skin integrity/sore } \\
\text { prevention/treatment }\end{array}$} & PGY1 & $14(25.9 \%)$ & $26(48.1 \%)$ & $14(25.9 \%)$ & 54 \\
\hline & $\begin{array}{c}\text { PGY2 \& } \\
\text { PGY3 }\end{array}$ & $25(28.4 \%)$ & $36(40.9 \%)$ & $27(30.7 \%)$ & 88 \\
\hline & Total & $39(27.5 \%)$ & $62(43.8 \%)$ & $41(28.9 \%)$ & 142 \\
\hline \multirow[t]{3}{*}{ Somatic pain } & PGY1 & $20(35.1 \%)$ & $27(47.4 \%)$ & $10(17.5 \%)$ & 57 \\
\hline & $\begin{array}{c}\text { PGY2 \& } \\
\text { PGY3 }\end{array}$ & $35(38.0 \%)$ & $36(39.1 \%)$ & $21(22.8 \%)$ & 92 \\
\hline & Total & $55(36.9 \%)$ & $63(42.3 \%)$ & $31(20.8 \%)$ & 149 \\
\hline \multirow[t]{3}{*}{ Neuropathic pain } & PGY1 & $12(20.7 \%)$ & $27(46.6 \%)$ & $19(32.8 \%)$ & 58 \\
\hline & $\begin{array}{c}\text { PGY2 \& } \\
\text { PGY3 }\end{array}$ & $16(17.0 \%)$ & $47(50.0 \%)$ & $31(33.0 \%)$ & 94 \\
\hline & Total & $28(18.4 \%)$ & $74(48.7 \%)$ & $50(32.9 \%)$ & 152 \\
\hline
\end{tabular}

*Analysis of level of comfort addressing this secondary complication by year of residency found that counts were too low for Chi Square statistic. 
Table 3: Level of Comfort in Evaluating Patients' Needs for Therapies, Equipment, and Services

\begin{tabular}{|c|c|c|c|c|c|}
\hline \multirow[b]{2}{*}{$\begin{array}{c}\text { Treatments being } \\
\text { evaluated }\end{array}$} & \multirow[b]{2}{*}{$\begin{array}{l}\text { Year of } \\
\text { Residency }\end{array}$} & \multicolumn{3}{|c|}{ Level of Comfort } & \multirow[b]{2}{*}{ Total N } \\
\hline & & $\begin{array}{c}\text { Uncomfortable } \\
\mathrm{n}(\%)\end{array}$ & $\begin{array}{c}\text { Somewhat } \\
\text { Comfortable } \\
\mathrm{n}(\%)\end{array}$ & $\begin{array}{c}\text { Comfortable } \\
\mathrm{n}(\%)\end{array}$ & \\
\hline \multirow[t]{3}{*}{ Mobility Devices* } & PGY1 & $33(64.7 \%)$ & $13(25.5 \%)$ & $5(9.8 \%)$ & 51 \\
\hline & $\begin{array}{l}\text { PGY2 \& } \\
\text { PGY3 }\end{array}$ & $52(66.7 \%)$ & $24(30.8 \%)$ & $2(2.6 \%)$ & 78 \\
\hline & Total & $85(65.9 \%)$ & $37(28.7 \%)$ & $7(6.4 \%)$ & 129 \\
\hline \multirow{3}{*}{$\begin{array}{c}\text { Home Health } \\
\text { Aides/Services }\end{array}$} & PGY1 & $26(48.1 \%)$ & $17(31.5 \%)$ & $11(20.4 \%)$ & 54 \\
\hline & $\begin{array}{c}\text { PGY2 \& } \\
\text { PGY3 }\end{array}$ & $42(46.7 \%)$ & $35(38.9 \%)$ & $13(14.4 \%)$ & 90 \\
\hline & Total & $68(47.2 \%)$ & $52(36.1 \%)$ & $24(16.7 \%)$ & 144 \\
\hline \multirow{3}{*}{$\begin{array}{l}\text { Durable Medical } \\
\text { Equipment }\end{array}$} & PGY1 & $26(53.1 \%)$ & $14(28.6 \%)$ & $9(18.4 \%)$ & 49 \\
\hline & $\begin{array}{l}\text { PGY2 \& } \\
\text { PGY3 }\end{array}$ & $45(53.6 \%)$ & $31(36.9 \%)$ & $8(9.5 \%)$ & 84 \\
\hline & Total & $71(53.4 \%)$ & $45(33.8 \%)$ & $17(12.8 \%)$ & 133 \\
\hline \multirow{3}{*}{$\begin{array}{c}\text { Home } \\
\text { Modifications* }\end{array}$} & PGY1 & $30(65.2 \%)$ & $11(23.9 \%)$ & $5(10.9 \%)$ & 46 \\
\hline & $\begin{array}{c}\text { PGY2 \& } \\
\text { PGY3 }\end{array}$ & $58(75.3 \%)$ & $15(19.5 \%)$ & $4(5.2 \%)$ & 77 \\
\hline & Total & $88(71.5 \%)$ & $26(21.1 \%)$ & $9(7.4 \%)$ & 123 \\
\hline \multirow{3}{*}{$\begin{array}{c}\text { Accessible } \\
\text { Transportation }\end{array}$} & PGY1 & $26(54.2 \%)$ & $15(31.3 \%)$ & $7(14.6 \%)$ & 48 \\
\hline & $\begin{array}{c}\text { PGY2 \& } \\
\text { PGY3 }\end{array}$ & $47(58.0 \%)$ & $25(30.9 \%)$ & $9(11.1 \%)$ & 81 \\
\hline & Total & $73(56.6 \%)$ & $40(31.0 \%)$ & $16(12.4 \%)$ & 129 \\
\hline \multirow{3}{*}{$\begin{array}{c}\text { Communication } \\
\text { Devices* }\end{array}$} & PGY1 & $30(73.2 \%)$ & $7(17.1 \%)$ & $4(9.8 \%)$ & 41 \\
\hline & $\begin{array}{c}\text { PGY2 \& } \\
\text { PGY3 }\end{array}$ & $49(71.0 \%)$ & $16(23.2 \%)$ & $4(5.8 \%)$ & 69 \\
\hline & Total & $79(71.8 \%)$ & $23(20.9 \%)$ & $8(7.3 \%)$ & 110 \\
\hline \multirow{3}{*}{$\begin{array}{l}\text { Occupational } \\
\text { Therapy }\end{array}$} & PGY1 & $17(32.7 \%)$ & $22(42.3 \%)$ & $13(25.0 \%)$ & 52 \\
\hline & $\begin{array}{l}\text { PGY2 \& } \\
\text { PGY3 }\end{array}$ & $37(45.1 \%)$ & $32(39.0 \%)$ & $13(15.9 \%)$ & 82 \\
\hline & Total & $54(40.3 \%)$ & $54(40.3 \%)$ & $26(19.4 \%)$ & 134 \\
\hline \multirow{3}{*}{$\begin{array}{c}\text { Speech and } \\
\text { Language Therapy }\end{array}$} & PGY1 & $14(28.6 \%)$ & $19(38.8 \%)$ & $16(32.7 \%)$ & 49 \\
\hline & $\begin{array}{c}\text { PGY2 \& } \\
\text { PGY3 }\end{array}$ & $33(38.4 \%)$ & $37(43.0 \%)$ & $16(18.6 \%)$ & 86 \\
\hline & Total & $47(34.8 \%)$ & $56(41.5 \%)$ & $32(23.7 \%)$ & 135 \\
\hline \multirow[t]{3}{*}{ Physical Therapy } & PGY1 & $6(11.1 \%)$ & $21(38.9 \%)$ & $27(50.0 \%)$ & 54 \\
\hline & $\begin{array}{c}\text { PGY2 \& } \\
\text { PGY3 }\end{array}$ & $13(14.4 \%)$ & $38(42.2 \%)$ & $39(43.3 \%)$ & 90 \\
\hline & Total & $19(13.2 \%)$ & $59(41.0 \%)$ & $66(45.8 \%)$ & 144 \\
\hline \multirow{3}{*}{$\begin{array}{c}\text { Vocational } \\
\text { Rehabilitation* }\end{array}$} & PGY1 & $34(81.0 \%)$ & $5(11.9 \%)$ & $3(7.1 \%)$ & 42 \\
\hline & $\begin{array}{c}\text { PGY2 \& } \\
\text { PGY3 }\end{array}$ & $48(76.2 \%)$ & $10(15.9 \%)$ & $5(7.9 \%)$ & 63 \\
\hline & Total & $82(78.1 \%)$ & $15(14.3 \%)$ & $8(7.6 \%)$ & 105 \\
\hline
\end{tabular}

*Analysis of level of comfort addressing this treatment evaluation by year of residency found that counts were too low for Chi Square statistic. 
